\title{
Sol-gel matrix for YAG:Ce phosphors in pc-LEDs
}

\author{
Gertrud Kräuter $^{1}$ - Angela Eberhardt ${ }^{1}$ - Florian Peskoller ${ }^{1}$. Nusret Sena Güldal ${ }^{1} \cdot$ Alfred Lell $^{1} \cdot$ Riina Ritasalo $^{2}$ \\ Tero Pilvi ${ }^{2} \cdot$ Manfred Römer ${ }^{3} \cdot$ Gerhard Domann $^{3} \cdot$ Peer Löbmann $\mathbb{D}^{3}$
}

Received: 31 October 2020 / Accepted: 15 December 2020 / Published online: 16 January 2021

(c) The Author(s) 2021

\section{Abstract}

Sol-gel formulations were applied to replace silicone as matrix material for phosphors in pc-LEDs. The content of organic groups was minimized in order to reduce yellowing during the operation of the elements. It was possible to evenly embed YAG:Ce particles in sol-gel binders. Further processing on LED chips resulted in operational light sources; and their performance was compared to standard silicone-based elements. Additional deposition of ALD laminates seals possible defects within the sol-gel matrix as additional protection of the phosphors and the underlying LEDs.

\section{Graphical Abstract}

In lighting technology, the emission of LEDs is converted into the visible range by fluorescent particles embedded in silicone. The thermal stability of silicone limits the operating temperature and thus the light intensity. By using innovative temperature-stable sol-gel matrix materials, commercial LED chips can be operated at higher currents and thus their emission is significantly increased.
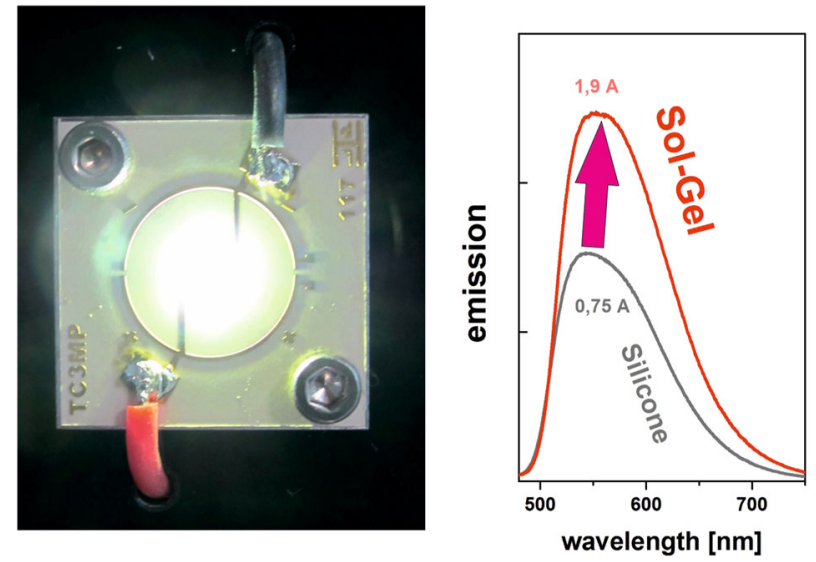

Keywords Sol-gel $\cdot$ Matrix material $\cdot \mathrm{pc}-\mathrm{LED} \cdot \mathrm{ALD}$

\section{Highlights}

- Sol-gel matrix materials for LED phosphors were synthesized.

- YAG:Ce particles were embedded in these matrices.

- LED chips with improved light emission compared to standard silicone matrix could be prepared.

- ALD was applied for additional phosphor encapsulation.

Peer Löbmann

peer.loebmann@isc.fraunhofer.de

1 OSRAM Opto Semiconductors GmbH, Leibnizstr. 4, 93055 Regensburg, Germany
2 Picosun Oy, Tietotie 3, 02150 Espoo, Finland

3 Fraunhofer ISC, Neunerplatz 2, 97082 Würzburg, Germany 


\section{Introduction}

Light-emitting diodes (LEDs) are rapidly replacing incanscent and fluorescent lamps due to their high efficiency, low power consumption, and long lifetime [1, 2]. White light may be generated by the simultaneous emission of red, green, and blue LEDs [3]. Alternatively, blue LEDs can be combined with down-converting phosphors such as Cerium-doped Yttrium aluminum garnet (YAG: Ce) [4]. For such devices the YAG:Ce particles are usually embedded in a silicone resin on top of the LED chips $[5,6]$. Even though the thermal output of the diode is by far lower than that of e.g. filament lamps, local temperatures of $150-200{ }^{\circ} \mathrm{C}$ may arise due to the small device size and poor thermal conductivity of the resins [7]. Under such conditions silicones easily disintegrate and turn yellow [8].

Different converters such as glass ceramics [6] or luminescent glasses $[9,10]$ that do not suffer from yellowing are under investigation. These materials, however, exhibit lower quantum efficiencies than YAG:Ce. Therefore, transparent matrix materials with a higher thermal stability than the stateof-the-art silicones are in demand.

Hybrid polymers [11] can cover a wide range of properties between organic polymers and purely inorganic materials. On the nanoscale, an inorganic $\mathrm{Si}-\mathrm{O}-\mathrm{Si}$ network is established by the hydrolysis and condensation of silicon alkoxides $\mathrm{Si}(\mathrm{OR})_{4}$; alkoxysilanes $\mathrm{R}^{\prime}-\mathrm{Si}(\mathrm{OR})_{3}$ can provide functional $-\mathrm{R}^{\prime}$ sidechains. In this context, the methyl group of $\mathrm{Me}-\mathrm{Si}(\mathrm{OR})_{3}$ is the simplest organic residue.

In silicones every repeat unit $-\left[\mathrm{OSiMe}_{2}-\right]$ carries two methyl groups per silicon atom. Compared to this the content of organic groups in hybrid polymers can largely be reduced when e.g., mixtures of $\mathrm{Si}(\mathrm{OR})_{4}$ and $\mathrm{MeSi}(\mathrm{OR})_{3}$ are employed in a sol-gel synthesis. Therefore, one can expect an improved thermal stability of hybrid polymers as compared to standard silicones. Hybrid polymers thus have a good prospects as matrix materials for the embedding of phosphors in pc-LEDs.

It has to be noted, though, that the final material properties critically depend on the precursor composition. Purely inorganic sol-gel materials [12], for example, are known to be brittle. Therefore, inorganic films often suffer from cracking due to tensile stresses during drying and thermal consolidation. The so-called critical film thickness of purely inorganic films in most cases is therefore below $1 \mu \mathrm{m}$. Maintaining some network flexibility [13], the incorporation of pre-condensed particles [14] or the use of stressrelaxing agents [15] can counteract this phenomenon. Such considerations must be taken into account in the design of sol-gel matrix materials.
Crystalline YAG:Ce particles are quite stable against environmental conditions that occur during normal operation of LEDs. As soon as alternate phosphors such as nitrides, oxyfluorides, or quantum dots $[16,17]$ are considered, though, barrier properties of the matrix materials become important. Additionally, the underlying LED chip and its lead frame may require protection. It is therefore essential that in addition to transparency and the mechanical carrier function, the desired sol-gel matrix envelops the phosphors without cracks.

\section{Experimental procedure}

\subsection{Sol-gel matrix material}

The synthesis of the sol-gel matrix is based on a procedure established by Jonschker et al. [18, 19]: First $3.26 \mathrm{~mol}$ $(580.56 \mathrm{~g})$ triethoxymethylsilane (MTEOS) are mixed with $0.816 \mathrm{~mol}(169.53 \mathrm{~g})$ tetraethoxysilane (TEOS). In a second vessel $0.78 \mathrm{~mol} \mathrm{H}_{2} \mathrm{O}(12.2 \mathrm{~g})$ are added to $250 \mathrm{~g}$ of a 30 mass \% aqueous solution of $\mathrm{SiO}_{2}$ particles $\left(1.25 \mathrm{~mol} \mathrm{SiO}_{2}\right.$ in $7.72 \mathrm{~mol} \mathrm{H}_{2} \mathrm{O}$ ). Under vigorous stirring this mixture was quickly added to the silanes and immediately adjusted to $\mathrm{pH}$ $1-2$ by a small amount of concentrated $\mathrm{HCl}$. After continued stirring for 5 min the product was cooled down in an ice bath, filtered through a $0.7 \mu \mathrm{m}$ glass fiber filter and stored at $-18^{\circ} \mathrm{C}$.

The silanes were purchased from Aldrich and used without further purification. The aqueous solution of $\mathrm{SiO}_{2}$ particles "Levasil 30/300" was supplied by Kurt Obermeier GmbH \& Co. KG (Bad Berleburg, Germany).

The amount of Si-Me groups provided by MTEOS can be reduced by variation of the MTEOS:TEOS ratio. In this procedure the quantity of $\mathrm{H}_{2} \mathrm{O}$ with respect to total number of Si-OEt groups (ROR-value) has to be maintained at 0.8 .

\subsection{YAG:Ce-matrix composites}

YAG:Ce particles with diameters $\mathrm{d}_{50}$ of 7 and $17 \mu \mathrm{m}$ (OSRAM GmbH, Germany) were dispersed in the sol-gel matrix material in different YAG:matrix mass ratios by manual stirring.

\subsection{Material deposition}

Borosilicate glass (Borofloat ${ }^{\bullet}$, thickness $3 \mathrm{~mm}$ ) was used as substrate after cleaning in a laboratory dish washer by using an alkaline detergent. Prior to the coating process, the substrates were additionally cleaned with compressed air. Films of pure matrix materials were deposited by spincoating, dried for $10 \mathrm{~min}$ at $80^{\circ} \mathrm{C}$ in a vented furnace before 
thermal treatment for $30 \mathrm{~min}$ in a pre-heated furnace at temperatures between 200 and $500{ }^{\circ} \mathrm{C}$.

YAG:Ce-matrix composites were applied by doctor blade coating. Due to sedimentation of the YAG particles the dispersions were freshly stirred immediately before film preparation. Drying and thermal treatment were performed as for the pure matrix films.

For functional tests InGaN-Chips (UX:3-Chips, $1 \mathrm{~mm}^{2}$ surface emitters, OSRAM GmbH, Germany) were coated by dropcasting with sol-gel composites containing 70 mass $\%$ YAG:Ce. These samples were heated up from room temperature to $150{ }^{\circ} \mathrm{C}(10 \mathrm{~K} / \mathrm{min}$, dwell time $2 \mathrm{~h})$ resulting in films with $\sim 100 \mu \mathrm{m}$ thickness.

\subsection{ALD processing}

Samples of YAG:Ce-matrix composites were placed on a pocket wafer for automatic loading. The Atomic layer deposition (ALD) process was made using a PICOSUN ${ }^{\oplus} \mathrm{R}$ 200 Advanced ALD reactor under reduced pressure $\left(\mathrm{N}_{2}\right.$ atmosphere) of about 1 mbar. The deposition was started with the growth of an alumina layer by repeatedly dosing $\mathrm{Al}$ precursor and oxidizer separated by $\mathrm{N}_{2}$ purge until $5 \mathrm{~nm}$ thickness was achieved. The same procedure was followed for hafnia. Deposition of the first and second material was then repeated 5 times (in the same reactor without any airbreak) resulting in $50 \mathrm{~nm}$ ALD-laminate.

\subsection{Material characterization}

The film thicknesses of sol-gel matrices and YAG:Ce-matrix composites were determined by an AlphaStep 200 Profilometer (KLA Tencor, Milpitas, USA). VK-X200KLaser scanning microscopy (LSM) was performed using a VKX200K (Keyence GmbH, Neu-Isenburg, Germany).

Scanning electron microscopy (SEM) images were taken using a Ultra 55 (Carl Zeiss NTS GmbH, Germany), a SU8230 (Hitachi, Japan), and a Cross Beam AURIGA 60 (Carl Zeiss NTS GmbH, Germany) scanning electron microscope, respectively, where the samples were cut in-situ by a $\mathrm{Ga}$ focussed ion beam (FIB). Other specimen were prepared by either mechanically fracturing or CSP (Cross Section Polisher SM-09010, JEOL, Freising, Germany) using an Ar beam).

The LED performance was tested by an emission spectrometer (instrument Systems, Optische Messtechnik GmbH, Munich, Germany).

\section{Results and discussion}

In conventional silicone resins two organic methyl groups are attached to silicon in the repeat unit $-\left[\mathrm{OSiMe}_{2}\right]-$. This accounts for matrix disintegration and yellowing [8] when used as matrix for YAG:Ce phosphors in white pc-LEDs. When sol-gel synthesis based on MTEOS, TEOS, and silica particles employed, this ratio can be significantly reduced. We chose an initial formulation, where one silicon atom statistically comes to only 0.61 methyl groups.

Sol-gel syntheses, however, differ in principle from the production of silicone resins. Ethanol is set free from the hydrolysis and condensation reaction. This volatile component must escape from the film during its manufacture. Therefore, shrinkage occurs perpendicular to the substrate plane. At the same time, a three-dimensional network is successively created due to the multiple reaction possibilities of the precursors. Consequently, tensile stresses parallel to the substrate plane occur within the film. When these stresses exceed the cohesive strength within the material, cracking of the film takes place [20-22].

The above considerations are especially important for mostly inorganic and thus brittle film materials. One strategy to increase the critical film thickness, above which cracking occurs, is to reduce brittleness by introducing non-condensing groups that preserve some flexibility. In our case the use of a fraction of MTEOS (Me-Si(OEt) $)_{3}$ ) serves this purpose. Additionally, pre-densified $\mathrm{SiO}_{2}$ particles ("LEVASIL"), that do not undergo shrinkage during film preparation, are employed. Such $\mathrm{SiO}_{2}$-based sol-gel matrix films were prepared by spin-coating. After drying at $80^{\circ} \mathrm{C}$, the samples were annealed at $300^{\circ} \mathrm{C}$. The resulting film thickness is displayed in Fig. 1a. The film thickness develops as a function of the spinning rate as one would expect from this setup: For a spinning rate of 300 RPM a film thickness of up to $6.8 \mu \mathrm{m}$ can be obtained, for spinning rates above 3000 RPM a constant film thickness of $\sim 2.5 \mu \mathrm{m}$ is established. The cross-sectional SEM view of a sample prepared with 5000 RPM appears homogeneous; no cracking becomes apparent. Because silicon is the main component of both the layer and the glass substrate, the image suffers from weak brightness contrast between the two areas, but the layer can be easily distinguished from the glass substrate by its different texture.

To do justice to the truth one has to admit that crosssectional SEM imaging of small sample spots easily suggests the absence of film defects. In fact, only large area imaging of film surfaces allows a reliable assessment of the extent of crack formation, the quantification of which is difficult [22]. Therefore, we have investigated larger sections $\left(50 \times 50 \mathrm{~mm}^{2}\right)$ of film surfaces with Laser Scanning Microscopy (LSM, data not shown). Here we distinguish between defect-free films, samples that show individual cracks, and surfaces where interconnected cracks separate distinct layer fields. These results are collected in Table 1 along with the respective final film thicknesses.

Thermal curing of sol-gel films is a dynamic process where removal of volatile components and network 
Fig. 1 Matrix film thickness as a function of spinning rate (a) and cross-sectional SEM image of a sample prepared with 5.000 RPM (b). All specimens have been annealed at $300^{\circ} \mathrm{C}$

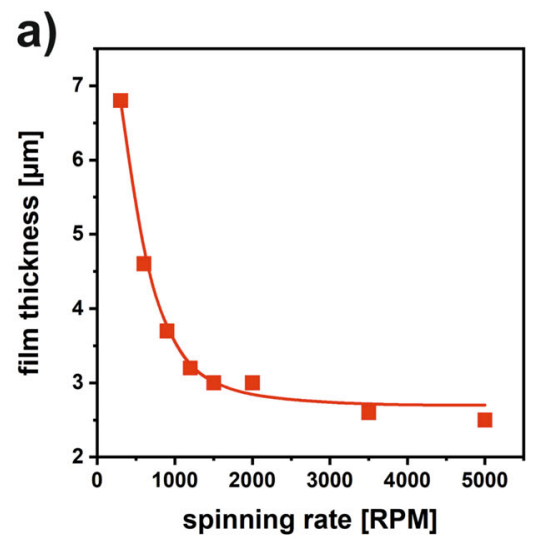

Table 1 Final film thickness in $[\mu \mathrm{m}]$ of sol-gel matrix films prepared with different spinning rates as a function of treatment temperature

\begin{tabular}{|c|c|c|c|c|c|c|c|c|}
\hline Spinning rate [RPM] & 300 & 600 & 900 & 1200 & 1500 & 2000 & 3500 & 5000 \\
\hline 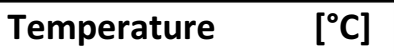 & & & & & & & & \\
\hline 80 & 6.4 & 4.2 & 3.8 & 3.2 & 2.8 & 2.5 & 2.4 & 2.4 \\
\hline 200 & 5.2 & 4.4 & 3.3 & 3.1 & 2.8 & 2.5 & 2.6 & 2.3 \\
\hline 250 & 5.5 & 4.7 & 3.7 & 3.2 & 3.0 & 2.6 & 2.0 & 2.2 \\
\hline 300 & 6.8 & 4.6 & 3.7 & 3.2 & 3.0 & 3.0 & 2.6 & 2.5 \\
\hline 350 & 6.1 & 4.2 & 3.8 & 3.5 & 2.8 & 2.9 & 2.4 & 2.2 \\
\hline 400 & 6.5 & 4.7 & 4.0 & 3.4 & 3.0 & 2.8 & 2.6 & 2.5 \\
\hline 450 & 6.7 & 4.7 & 3.9 & 3.3 & 3.0 & 2.9 & 2.7 & 2.5 \\
\hline 500 & 6.9 & 5.5 & 3.6 & 3.3 & 3.1 & 3.0 & 2.5 & 2.5 \\
\hline
\end{tabular}

The values of defect-free samples are highlighted in green, those with separated cracks in gray. Samples, where interconnected cracks separate distinct layer fields, are labeled red

formation occur simultaneously. The investigated samples were treated by placing them in a pre-heated oven, whereby the layers experience high heating rates. Under these conditions, it can be assumed that a regime "drying before gelation" as classified by Cairncross et al. [23] is established.

The table describes the quality of the layers as a function of the thickness after film deposition (spin speed) and treatment temperature. As a general trend, thinner asdeposited films (high spinning rates) are less prone to defect formation. This is directly understandable because they undergo less densification and thus suffer from less tensile stresses. It should be noted that the determination of the coating thickness by profilometry is probably subject to a measurement inaccuracy of $0.1-0.2 \mu \mathrm{m}$.

The dependence on the temperature is not so straightforward to describe: Samples prepared at 1500 RPM, for example, do not crack up to a treatment temperature of $200{ }^{\circ} \mathrm{C}$. Between 200 and $400{ }^{\circ} \mathrm{C}$, a maximum of the defect formation is passed through, whereas on the other hand, crack-free samples are obtained again at higher temperatures. It can be assumed that at lower temperatures the material is not yet fully cross-linked and the remaining flexibility prevents the formation of cracks by structural relaxation. In the medium temperature range, a rigid network has already formed at the film surface, while the removal of volatile components and reaction products, especially from deeper layer regions, is not yet complete. Cracks will initiate at the brittle surface. When the asdeposited samples are rapidly exposed to temperatures above $450{ }^{\circ} \mathrm{C}$, the whole film is densified, and consolidation and densification are balanced.

In summary, it is important to note that thick and defect-free matrix films can be prepared whose thermal stabilities clearly exceeds those of silicones. In contrast to silicones, that contain 2 methyl groups per $\mathrm{Si}$, our initial formulation contains an average ratio of 0.61 : 1 . It is possible to reduce this ratio to $0.16: 1$ by decreasing the amount of MTEOS used in the synthesis. But now it is of crucial importance how YAG particles can be incorporated into the matrix and what the properties of the resulting composite layers are. 
Fig. 2 SEM top views of composite films containing 20 mass\% (a), 50 mass\% (b), and 70 mass\% (c) YAG:Ce

phosphor particles in a sol-gel matrix. All samples have been annealed at $150^{\circ} \mathrm{C}$
Fig. 3 SEM image of the fractured surface of a composite film containing 50 mass\% YAG: Ce (left) and sample prepared by FIB cutting at higher magnification (right)
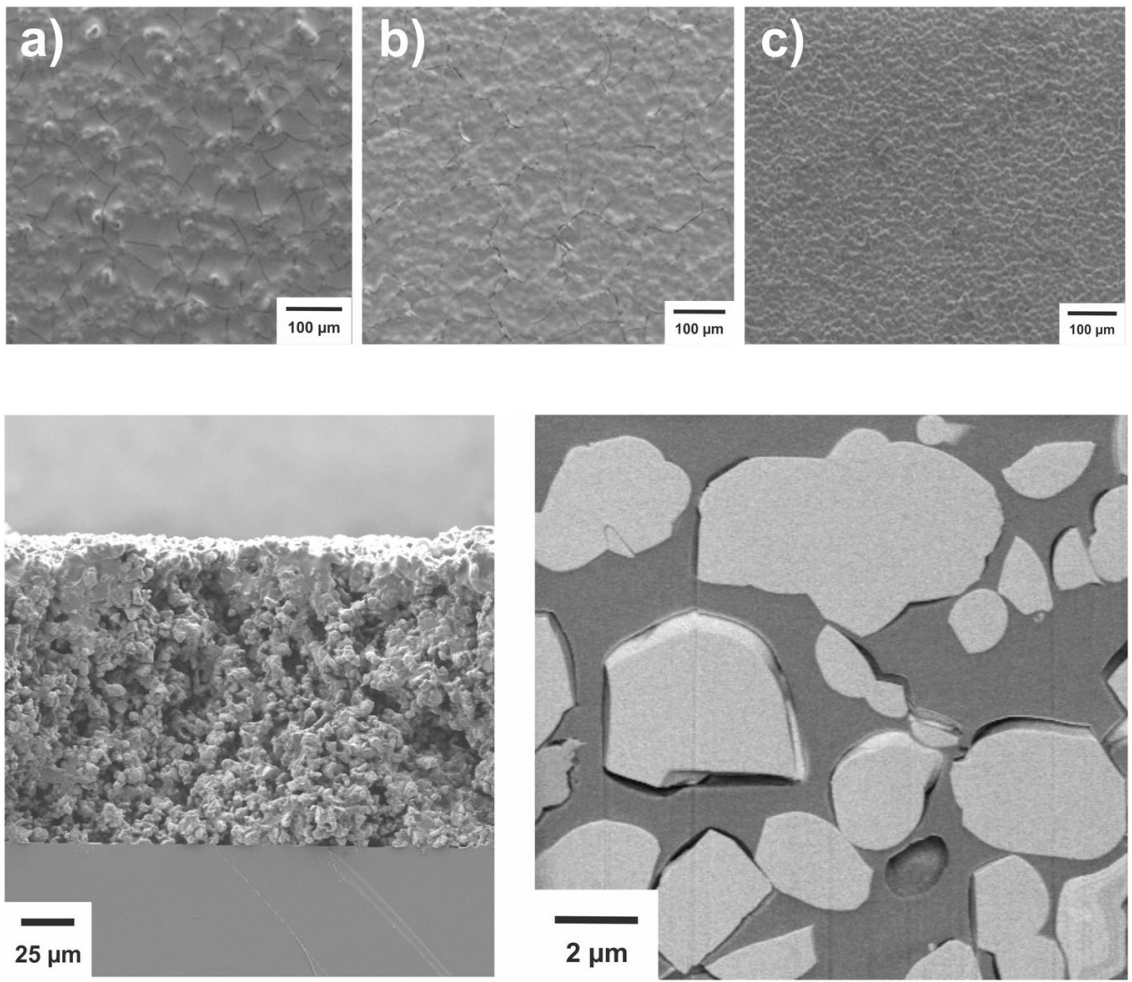

YAG:Ce particles were mechanically stirred into matrix sols in mass ratios from $20 \%$ up to $80 \%$. The viscosities of the sols are in the range of $0.01-0.02 \mathrm{~Pa}$, therefore they slow down the sedimentation of the YAG particles $\left(\mathrm{d}_{50}\right.$ $7-17 \mu \mathrm{m})$ only slightly. The character of the mixture is therefore more like a slurry than a stable dispersion, and rapid processing is appropriate. One could try to improve this property by adding viscous additives such as PEG. However, such a procedure would contradict the goal of a low organic content of the matrix. Later thermal burn-out of such components could also cause porosity in the composite. It seems therefore advantageous to deal with the described disadvantages of the YAG dispersion.

Doctor-blading proved to be more suitable for the production of composite layers than the spin-coating process used for pure matrix films. Figure 2 shows surface images of coatings prepared from dispersions with different YAG:Ce contents. In all images bulges, presumably from underlying YAG:Ce particles, can be seen. The average distance between the protrusions decreases when the particle content is increased. The surface of the composite film containing 20 mass\% YAG:Ce shows several cracks, which sometimes merge into each other. The extent of these defects is considerably smaller, when 50 mass $\%$ are employed. The surfaces of composite films that were prepared using dispersions that contain 70 mass\% YAG:Ce are completely crack-free.

The production of composite films obeys the same principles that were already mentioned for the pure matrix films: The installation of the rigid YAG:Ce phosphor particles reduces the shrinkage of the film; tensile stresses and associated crack formation are minimized. As the space between YAG:Ce grains decreases due to the higher load, the sol-gel matrix has to bridge smaller distances. In this respect the YAG:Ce particles in the composite films perform the same function as the $\mathrm{SiO}_{2}$ particles from "Levasil" in the pure matrix layers.

The cross-sectional image in Fig. 3 reveals that the composite coatings with $\sim 125 \mu \mathrm{m}$ can be prepared significantly thicker than the pure matrix films. Due to the roughness of the fracture surface, the image gives the impression of a high layer porosity. Therefore, a cross section of the sample was prepared by FIB technique and examined at higher magnification. This cross section shows a firm integration of the YAG:Ce grains into the sol-gel matrix. Individual gaps in between the surface of the particles and the matrix may be induced by the heat input of the Ga-beam during sample preparation [24]. However, the rough surface of the mechanically generated fracture surface is obviously caused by the breaking out of particle agglomerates.

In addition to the mechanical integration into the matrix, the question of its protective function for the fluorescent particles and for the underlying LED chip against the ambient atmosphere arises. This may become especially important for next-generation LEDs which use more sensitive converters such as quantum dots or nitrides $[16,17]$. 


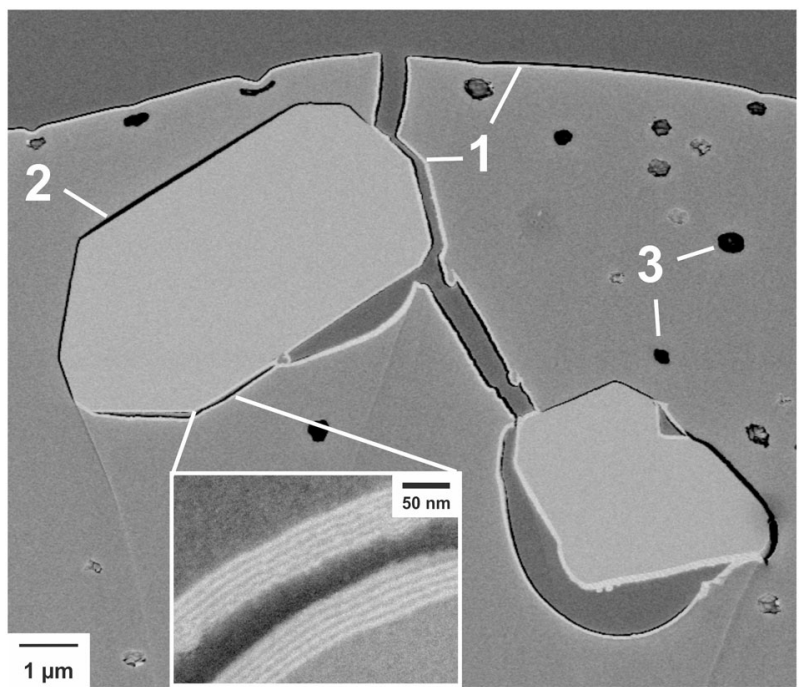

Fig. 4 SEM image of a composite film after ALD deposition. The specimen was prepared by cross-section polishing using an $\mathrm{Ag}$ beam. See text for details

Oxygen and humidity permeation measurements would therefore be obviously appropriate, but the materials are too brittle to prepare specimen suitable for such measurement setups. Ellipsometric porosimetry [25] could be used to characterize the water vapor condensation into possible pores of the matrix films. Unfortunately, these films are too thick for such a measurement and their refractive index contrast to the glass substrates is too low.

ALD [26] is a versatile tool to deposit dense and conformal barrier films of e.g. alumina [27], hafnia [28], or hafnia-silica laminates $[28,29]$. Apart from the additional application of protective layers on our composites, investigations on the penetration of the gaseous ALD precursors used can allow conclusions about the tightness of the matrix materials.

At the edges of doctor-bladed samples some surface cracking may occur as the local film thickness exceeds $200 \mu \mathrm{m}$. We purposely chose such a specimen and applied a tenfold ALD procedure of alternate alumina and hafnia deposition of $5 \mathrm{~nm}$ each. For our processing temperature of $150{ }^{\circ} \mathrm{C}$ it is known that these compositions are formed in their amorphous phase [26]. The SEM overview of the cross section in Fig. 4 shows that both the outer surface and the crack surfaces open to the outside are coated (1). But there are also voids between the YAG:Ce particles and the matrix (2) where both materials remain uncovered by ALD. In these regions, the sol-gel material obviously provides effective protection against the access of gaseous media. Also within closed pores (3) no material deposition takes place.

An enlargement of a section shows the lamellar structure of the ALD coating. Because of the comparable atomic numbers of their main components, the first alumina coating on the YAG:Ce and sol-gel matrix material

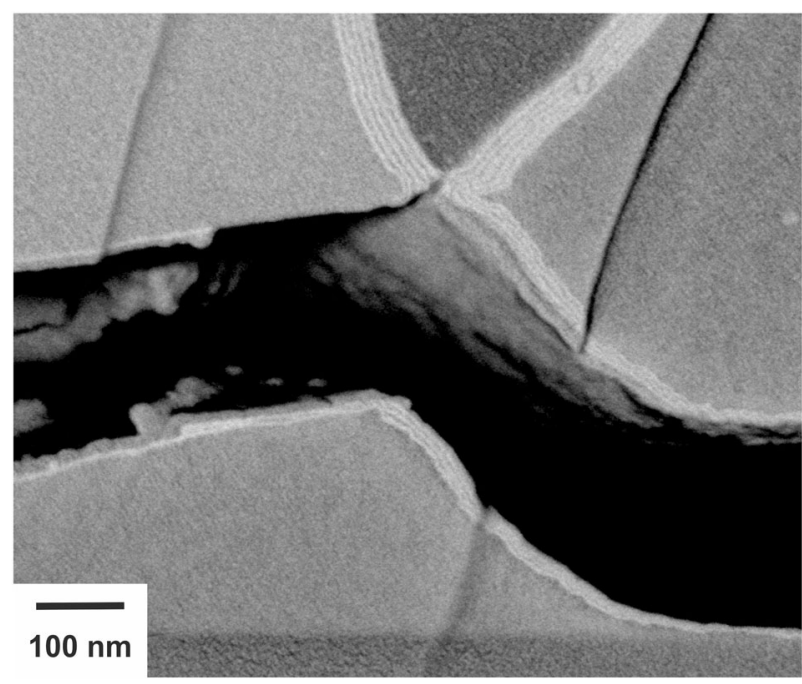

Fig. 5 SEM cross section image of a composite film after ALD deposition

is hardly visible, while the second hafnia coating appears much brighter.

The upper part of Fig. 5 shows a V-shaped crack that tapers downwards. Its inner side is evenly coated with the ALD material; the laminates on both walls of the crack meet at its narrowest point at the bottom. This constriction of the crack coming from above reaches down to a horizontal cavity; the original access to it is now closed by the ALD deposition. The inner surface of the lower cavity is only partially covered with less than 10 of the ALD laminate layers, preferably near the former gap. Figure 5 shows how ALD has sealed a crack within the YAG:Ce matrix composite, blocking access to the surrounding atmosphere. This is a particularly impressive example of how sol-gel matrix and ALD complement each other in terms of their blocking effect.

For functional tests composites of YAG:Ce phosphors (70 mass\%) in a sol-gel matrix were drop-casted on LEDchips $\left(1 \times 1 \mathrm{~mm}^{2}\right)$ as shown in the left part of Fig. 6 . After curing at $150{ }^{\circ} \mathrm{C}$ the film remains adherent and results in a functional device (right part).

The standard pc-LEDs under investigation using silicones as matrix material for their YAG:Ce phosphors are operated with $0.75 \mathrm{~A}$. At higher currents the LED temperatures exceeds $150{ }^{\circ} \mathrm{C}$ causing degradation and yellowing of the PDMS matrix. In the left part of Fig. 7 the emission of such a device is shown. After $1500 \mathrm{~h}$ operating time a slight decrease in emission due to aging phenomena is observed

In contrast to the silicone-based devices LEDs using the sol-gel matrix material can be run at $1.9 \mathrm{~A}$ which leads to a strongly enhanced brightness. Despite the more stringent conditions, even after $1500 \mathrm{~h}$ of operation, only a moderate reduction in emission is evident (right part of Fig. 7). This observation is presumably due to the reducing of the 
Fig. 6 Photography of a LED chip coated by a composite of YAG:Ce phosphors and a sol-gel matrix (left) and this device under operation (right)
Fig. 7 Emission spectrum of a pc-LED prepared with a standard silicone matrix operated at $0.75 \mathrm{~A}$ (left) compared to an element based on a sol-gel matrix operated at 1.9 A (right). The initial emissions (black lines) are compared to those after $1500 \mathrm{~h}$ (red lines), respectively
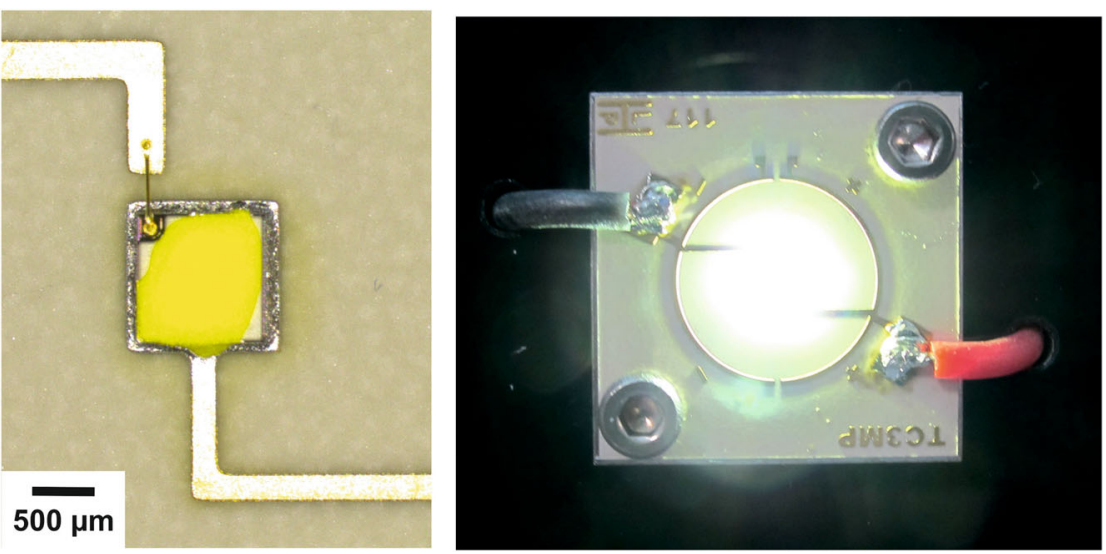

silicone matrix

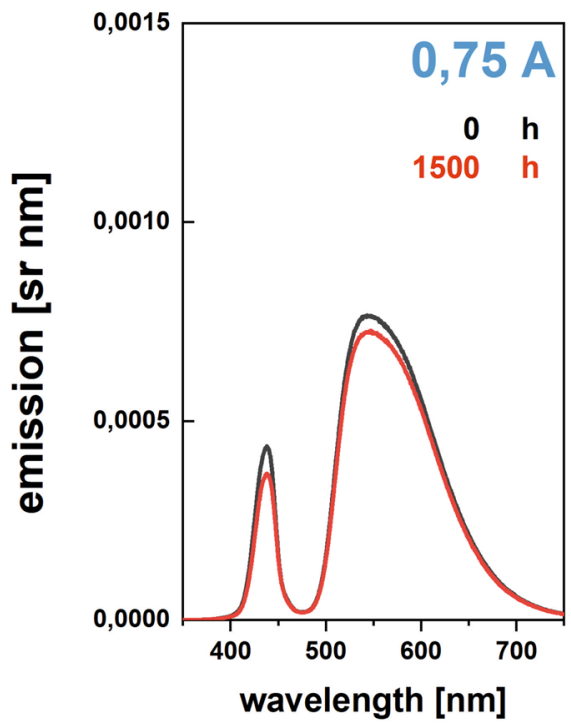

sol-gel matrix

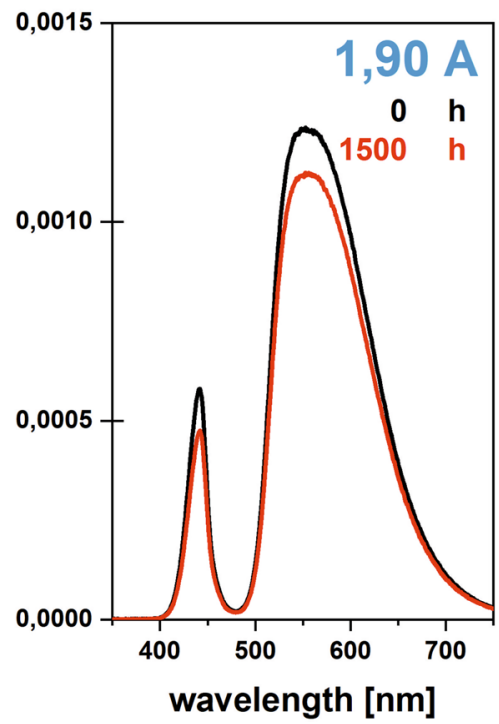

methyl/Si ratio from 2 (PDMS) to 0.61 and even 0.16 for the sol-gel matrix. Our sol-gel material clearly outperforms the previous state-of-the-art silicones.

\section{Conclusions}

Conventional silicones can successfully be replaced by sol-gel materials as a matrix for phosphors in LED illumination elements. The latter exhibit superior properties in terms of thermal stability and low content of organic groups. The phosphor is evenly integrated into the sol-gel material and protected against the ingress of gaseous media, a property that can be particularly important for next-generation LEDs. A further barrier effect can be achieved by the additional application of an ALD laminate. The LEDs based on sol-gel matrices can be operated at higher currents and thus clearly outperform that of their counterparts which use conventional silicones for embedding the YAG phosphors.

Acknowledgements The authors thank Adelheid Martin (ISC Würzburg, Germany) for her dedicated experimental support. We are grateful to Rolandas Tomašiūnas and Edvinas Radiunas (University of Vilnius, Lithuania) for providing some of the SEM results.

Funding This work was funded by the German Federal Ministry of Education and Research (Project "FLINGO" grant 13N14158) and the Finnish National Funding Agency (Dnro 4068/31/2015). Open Access funding enabled and organized by Projekt DEAL.

\section{Compliance with ethical standards}

Conflict of interest The authors declare that they have no conflict of interest.

Publisher's note Springer Nature remains neutral with regard to jurisdictional claims in published maps and institutional affiliations. 
Open Access This article is licensed under a Creative Commons Attribution 4.0 International License, which permits use, sharing, adaptation, distribution and reproduction in any medium or format, as long as you give appropriate credit to the original author(s) and the source, provide a link to the Creative Commons license, and indicate if changes were made. The images or other third party material in this article are included in the article's Creative Commons license, unless indicated otherwise in a credit line to the material. If material is not included in the article's Creative Commons license and your intended use is not permitted by statutory regulation or exceeds the permitted use, you will need to obtain permission directly from the copyright holder. To view a copy of this license, visit http://creativecommons. org/licenses/by/4.0/.

\section{References}

1. Jinmin L, Zhe L, Zhiqiang L et al. (2016) Advances and prospects in nitrides based light-emitting-diodes. J Semiconductors 37:61001. https://doi.org/10.1088/1674-4926/37/6/061001

2. Taki T, Strassburg M (2020) Visible LEDs: More than Efficient Light. ECS J Solid State Sci Technol 9:15017

3. Pimputkar S, Speck JS, DenBaars SP et al. (2009) Prospects for LED lighting. Nat Photonics 3:180-182

4. Yuhua W, Ge ZHU, Shuangyu XIN et al. (2015) Recent development in rare earth doped phosphors for white light emitting diodes. J Rare Earths 33:1-12

5. Luo X, Hu R (2014) Chip packaging: encapsulation of nitride LEDs. In: Nitride semiconductor light-emitting diodes (LEDs). Elsevier, Cambridge, pp 441-481

6. Chen D, Xiang W, Liang X et al. (2015) Advances in transparent glass-ceramic phosphors for white light-emitting diodes-a review. J Eur Ceram Soc 35:859-869

7. Lin H, Hu T, Cheng Y et al. (2018) Glass ceramic phosphors: towards long-lifetime high-power white light-emitting-diode applications-a review. Laser Photonics Rev 12:1700344

8. Wei N, Lu T, Li F et al. (2012) Transparent Ce: Y3Al5O12 ceramic phosphors for white light-emitting diodes. Appl Phys Lett 101:61902

9. Zhang X, Huang L, Pan F et al. (2014) Highly thermally stable single-component white-emitting silicate glass for organic-resinfree white-light-emitting diodes. ACS Appl Mater interfaces 6:2709-2717

10. Chung WJ, Nam YH (2019) A review on phosphor in glass as a high power LED color converter. ECS J Solid State Sci Technol 9:16010. https://doi.org/10.1149/2.0142001JSS

11. Haas K-H, Rose K (2003) Hybrid inorganic/organic polymers with nanoscale building blocks: precursors, processing, properties and applications. Rev Adv Mater Sci 5:47-52

12. Schneller T, Waser R, Kosec M et al. (2013) Chemical solution deposition of functional oxide thin films. Springer Vienna, Vienna, s.1.
13. Seco AM, Gonçalves MC, Almeida RM (2000) Densification of hybrid silica-titania sol-gel films studied by ellipsometry and FTIR. Mater Sci Eng 76:193-199

14. Schmidt H (2000) Sol-gel derived nanoparticles as inorganic phases in polymer-type matrices. Macromol Symp 159:43-56. https://doi.org/10.1002/1521-3900(200010)159:1<43:AIDMASY43>3.0.CO;2-0

15. Kozuka H, Takenaka S, Tokita H et al. (2003) Stress and cracks in gel-derived ceramic coatings and thick film formation. J Sol-Gel Sci Technol 26:681-686

16. Shirasaki Y, Supran GJ, Bawendi MG et al. (2013) Emergence of colloidal quantum-dot light-emitting technologies. Nat Photonics 7:13

17. Xie R-J, Hirosaki N (2017) Phosphors and White LED Packaging. In: Seong T-Y, Han J, Amano H et al. (eds) III-nitride based light emitting diodes and applications, Second edition, 133. Springer, Singapore, pp 397-432

18. Mennig M, Jonschker G, Schmidt HK (1992) Sol-gel-derived thick coatings and their thermomechanical and optical properties. In: Mackenzie JD (ed) Sol-Gel Optics II. SPIE, Saarbrücken, p 125

19. Jonschker G (1998) Synerese und Relaxationsverhalten von Sol-Gel Materialien. Universität des Saarlandes, Boston

20. Kozuka H (2005) Fundamental issues on solgel coatings: Stress evolution, cracking and radiative striations. Sol-Gel Process $1: 247-289$

21. Bockmeyer M, Löbmann P (2006) Densification and Microstructural Evolution of TiO2 Films Prepared by Sol- Gel Processing. Chem Mater 18:4478-4485

22. Bockmeyer M, Löbmann P (2007) Crack formation in $\mathrm{TiO} 2$ films prepared by sol-gel processing: quantification and characterization. Thin Solid Films 515:5212-5219

23. Cairncross RA, Francis LF, Le S (1996) Predicting drying in coatings that react and gel: drying regime maps. AIChE J 42:55-67

24. Giannuzzi LA, Prenitzer BI, Kempshall BW (2005) Ion-solid interactions. In: Introduction to focused ion beams. Springer, Berlin, pp 13-52

25. Löbmann P (2017) Characterization of sol-gel thin films by ellipsometric porosimetry. J Sol-Gel Sci Technol 84:2-15

26. Miikkulainen V, Leskelä M, Ritala M et al. (2013) Crystallinity of inorganic films grown by atomic layer deposition: overview and general trends. J Appl Phys 113:21301. https://doi.org/10.1063/1. 4757907

27. Carcia PF, McLean RS, Reilly MH et al. (2006) Ca test of Al2O3 gas diffusion barriers grown by atomic layer deposition on polymers. Appl Phys Lett 89:31915. https://doi.org/10.1063/1.2221912

28. Reklaitis I, Radiunas E, Malinauskas T et al. (2020) A comparative study on atomic layer deposited oxide film morphology and their electrical breakdown. Surf Coat Technol 399:126123

29. Jeong J, Laiwalla F, Lee J et al. (2018) Conformal hermetic sealing of wireless microelectronic implantable chiplets by multilayered atomic layer deposition (ALD). Adv Funct Mater 2:1806440. https://doi.org/10.1002/adfm.201806440 